\title{
A EDUCAÇÃO AMBIENTAL NAS PROPOSTAS FORMATIVAS DOS CURSOS DE PEDAGOGIA: DESAFIOS E EXPERIÊNCIAS DESENVOLVIDAS NO ESTADO DO PARANÁ
}

\author{
Marília Andrade Torales Campos ${ }^{1}$; Daniele Saheb ${ }^{2}$; Andréa Macedônio de Carvalho ${ }^{3}$
}

\begin{abstract}
RESUMO
Este artigo trata de analisar uma experiência de formação desenvolvida com estudantes do curso de Pedagogia de uma universidade pública no Estado do Paraná (Brasil). A partir do relato da experiência foram abordadas quatro ancoragens propostas por Girault et al (2006), ou seja, foram analisadas as seguintes dimensões da experiência: epistemológica, didática, curricular e pedagógica. Os dados apontam para a importância da inserção da temática ambiental nos cursos de formação de professores, em especial, no que se refere a formação dos professores que atuam na Educação Infantil e nos Anos Iniciais do Ensino Fundamental.

Palavras-chave: Formação de professores, Curso de Pedagogia, Educação Ambiental.
\end{abstract}

\begin{abstract}
This paperanalyzes a training experiencedevelopedwithstudents of the Pedagogy course of a public university in Paraná (Brazil). From the experience report, four anchoragesproposed by Girault et al (2006) wereapproached, thatis, the following dimensions of experiencewereanalyzed:epistemological, didactic, curricular and pedagogical. The data point to the importance of insertion of the environmentaltheme in teacher training courses, especially in the training of teacherswhowork in EarlyChildhood Education and in the EarlyYears of Elementary Education.
\end{abstract} Key words: Teacher training, Pedagogy course, Environmental Education.

\section{INTRODUÇÃO}

A Educação Ambiental tornou-se, nas últimas décadas, um campo de conhecimento extremamente necessário em virtude dos graves problemas ambientais que, cada vez mais, afetam a vida dos povos em todo o planeta. Defendemos a necessidade de uma Educação Ambiental Crítica, que exija uma postura política por parte do educador na busca da emancipação dos sujeitos e que, portanto, pressuponhaa união entre a teoria e a prática na atividade pedagógica.

\footnotetext{
${ }^{1}$ Professora Adjunta da Universidade Federal do Paraná. Doutora em Ciências da Educação. Email: mariliat.ufpr@gmail.com

${ }^{2}$ Professora da Pontifícia Universidade Católica do Paraná. Doutora em Educação. Email: danisaheb@yahoo.com.br

${ }^{3}$ Mestranda do Programa de Pós-Graduação em Educação da Universidade Federal do Paraná. Bolsista CAPES. Email: andrea.macedonio.carvalho@gmail.com
} 
As questões ambientais nas escolas, no entanto, ainda estão muito vinculadas às datas comemorativas, como o Dia do Meio Ambiente, Dia da Árvore e aos cuidados com o lixo e economia de água, conforme demonstram os estudos de Henn e Bastos (2008). É evidente perceber, como também demonstram os ensaios de Teixeira e Oliveira (2008), Ferreira (2011), Sato et al (2013) e Soczek e Haiduke (2013), que os professores ainda se sentem despreparados para trabalhar a educação ambiental porque não consideram ter tido uma formação adequada para abordar o tema em sala de aula.

Em decorrência desse despreparo dos professores na área ambiental, é comum, no âmbito escolar, a temática ambiental ser reduzida à superficialidade ou ao preservacionismo, reduzida ao discurso do "politicamente correto", não avançando na profundidade requerida por este debate (SOCZEK; HAIDUKE, 2013).

Esta dificuldade, oriunda da falta de formação e informação, como afirmado pelos autores acima, faz com que a maioria das atividades acabe se encerrando nelas mesmas, sem uma conexão com outros assuntos ou com um aprofundamento. Sobre isso, Teixeira e Oliveira $(2008$, p. 2) alertam para o fato de que "a temática ambiental se impõe sobre a educação escolar. Justifica-se, então, a preocupação com a formação do conhecimento dos professores sobre a temática ambiental".

A formação inicial de professores para atuar nos Anos Iniciais do Ensino Fundamental e na Educação Infantil se apresenta como um desafio para as instituições formadoras que tiveram suas propostas curriculares reorientadas a partir das novas diretrizes curriculares dos cursos de Pedagogia.As atuais normativas e políticas educacionais brasileiras apontam para a formação de profissionais competentes em diversas e complexas dimensões do processo formativo da infância, exigindo o avanço nas propostas curriculares dos cursos de Licenciatura.

Apesar da fragilidade demonstrada pelos professores para avançar nos processos educativo-ambientais, a formação ambiental de profissionais de todos os níveis é garantida pela Lei $\mathrm{n}^{\circ}$ 9.795, de 27 de abril de 1999 que, em seu Artigo 10, parágrafo 3ㅜ, diz que:

(...) nos cursos de formação e especialização técnico-profissional, em todos os níveis, deve ser incorporado conteúdo que trate da ética ambiental das atividades profissionais a serem desenvolvidas (BRASIL, 1999).

No caso específico do curso de Pedagogia, que dá licença ao profissional para exercer a docência na Educação Infantil e anos iniciais do Ensino Fundamental, o 
Parecer CNE/CP n ${ }^{\circ}$ 5/2005, que discorre sobre as Diretrizes Curriculares Nacionais para o Curso de Pedagogia, determina que:

(...) a educação do licenciado em Pedagogia deve, pois, propiciar, por meio de investigação, reflexão crítica e experiência no planejamento, execução, avaliação de atividades educativas, a aplicação de contribuições de campos de conhecimentos, como o filosófico, o histórico, o antropológico, o ambiental-ecológico (...) (MEC, 2005, p. 2)

Apesar de o mesmo documento afirmar que na organização curricular do curso de Pedagogiadeverá ser contemplada, dentre inúmeros outros aspectos, a preservação do meio ambiente, em termos de orientações legais nacionais para a elaboração curricular dos cursos de Pedagogia, estas são as únicas referências feitas à contemplação do tema ambiental na grade.

No Brasil, no entanto, a Educação Ambiental aparece na legislação desde 1973, como atribuição da primeira Secretaria Especial do Meio Ambiente (SEMA), mas é principalmente nas décadas de 1980 e 1990, com o avanço da consciência ambiental, que a Educação Ambiental cresce e se torna mais conhecida.

No estado do Paraná, especificamente, em 11 de janeiro de 2013, foi promulgada a Lei 17.505, que institui a Política Estadual de Educação Ambiental e o Sistema de Educação Ambiental que definem, assim como as leis nacionais, que todos têm direitos e deveres em relação à Educação Ambiental, como promover a educação ambiental em todos os níveis de ensino e o engajamento da sociedade na preservação e conservação, recuperação e melhoria do meio ambiente. Além disso, em seu parágrafo 6, artigos $1^{\circ} \mathrm{e}$ $2^{\circ}$, alguns deveres da Política Estadual de Educação Ambiental são definidos, como:

\footnotetext{
I - promover a educação ambiental em todos os níveis de ensino (...);

II - promover e desenvolver a educação ambiental de maneira integrada, interdisciplinar e transversal no currículo escolar, bem como integrá-la como prática e princípio educativo contínuo e permanente, em todos os níveis e modalidades do ensino formal (BRASIL, Lei $\mathrm{n}^{\mathbf{0}} 17.505,2013$ ).
}

Por outro lado, em seu texto, a lei define também, a obrigatoriedade da formação ambiental em todos os cursos profissionalizantes, além de formação continuada após a formação dos profissionais, o que significa um grande avanço para impulsionar aspropostas formativas e responsabilizar as instituições.

Neste contexto, problematizamos a formação dos professores no que se refere a sua preparação para atuar no campo da Educação Ambiental, tendo em vista que esses 
profissionais são elementos fundamentais para a ampliação dos debates sobre a problemática ambiental na escola. No caso da Educação Ambiental, a falta de uma formação e de suportes pedagógicos necessários para efetivar o labor cotidiano nas escolas se manifesta nas dificuldades encontradas para realizar um trabalho pluridisciplinar, que aborde o tema de maneira integrada, complexa e a partir de uma abordagem crítica.

O estudo documental apresentado por Álvarez-Garcia, Sureda-Negra e ComasFormas (2015) conclui que, sendo a Educação Ambiental um tema presente nos debates sobre a formação de professores em2014, as questões abordadas a partir da década de 1970 foram essencialmente de natureza teórica, priorizando um determinado tipo de formação. As propostas mais recentes se aproximam mais do campo empírico e de uma formação mais ampla em relação ao tema, no entanto, ainda não produzem resultados suficientes diante da responsabilidade e do inegável e importante papel dos professores em relação à formação das novas gerações, seja pelo pouco conhecimento ambiental ou pela baixa literacia ambiental.

Nesta mesma linha, Girault et al (2006) chamam a atenção para a necessidade de uma reflexão profunda para que seja levada em consideração a demanda de acompanhamento pedagógico dos professores não só em sua formação inicial, mas também de suas práticas profissionais. Segundo os autores, a necessidade de uma ação inter, multi, pluri e transdisciplinar no campo da Educação Ambiental contrasta com aproliferação de propostas formativas altamente disciplinarizadas e distantes desta perspectiva integradora e mais complexa. Ao mesmo tempo, em seu texto é possível perceber que, em diversas experiências, se apresentam elementos que remetem a identificação de certa forma de ativismo individual, social ou pedagógico, que contribui de forma fragmentada e pontual na formação integral dos professores.

Não seria adequado negar que existem elementos da tradição acadêmica que estão profundamente enraizados na cultura das instituições de ensino. O regramento de rotinas, de grades disciplinares, da distribuição de cargas horárias,as estruturas das disciplinas e de seus conteúdos, a formação dos professores formadores, as burocracias institucionais, as avaliações internas e externas etc. se constituem em um conjunto de matizes que desenham um cenário múltiplo e que exige um esforço mais profundo para sua compreensão. No caso específico do curso de Pedagogia, seria preciso pensar na 
preparação para a docência dos Anos Iniciais do Ensino Fundamental e da Educação Infantil como elementos centrais do processo de formação dos estudantes, futuros professores, pois no processo de ensino se alicerça sua principal função profissional, com vista a uma formação qualificada e integral dos sujeitos.

Ao pensar a construçãodo campo da educação ambiental como um processo recente e que ainda carece de avanços teóricos e práticos, emerge um cenário pedagógico diverso, fundamentado em sua origem no ativismo ecológico e social, sustentado por pautas reivindicativas de novos valores em relação a natureza e de práticas sociais engajadas e comprometidas com o ideário ambientalista. Neste sentido, valeria sublinhar que a inserção da Educação Ambiental nos múltiplos espaços de vida e especialmente nos espaços educativo-formais, em que os professores desenvolvem sua ação profissional, pode apontar para um cenário de alternativas futuras(CAMPOS; CARVALHO, 2015).

É preciso repensar o papel das instituições de ensino superior e das escolas de Magistério no que se refere a formação dos professores no campo da Educação Ambiental. Os estudos de Berryman (2006) propõem uma discussão sobre o processo de institucionalização da temática ambiental no contexto de formação de professores no Québec (Canadá). Segundo o autor, a formação de professores tem por base a gênese de sistemas altamente institucionalizados e focado em processos individuais. E, sob sua perspectiva e argumentos, seria preciso criar um espaço-tempo para a formação de professores que integrasse o meio ambiente aos fundamentos da educação para além dos próprios fundamentos da didática nas práticas pedagógica de ensino.

Sobre a possibilidade de propor novos cenários formativos, Girault et al (2006) propõem quatro pontos de referência, ou âncoras, para repensar os modelos de formação dos professores. Sinteticamente, essas âncoras seriam de natureza epistemológica, didática, curricular e pedagógica, conforme segue a descrição a seguir:

1. Ancoragem epistemológica: considerando a multiplicidade de abordagens que se referem ao conceito de Educação Ambiental, seria preciso estabelecer alguns limites epistemológicos em relação a compreensão do tema e a construção do conceito. Segundo o autor, tendo em conta o novo status epistemológico do meio ambiente, que se torna um objeto de natureza/cultura híbrida, poderá levar a convulsões nas práticas, em 
particular uma mudança em relação ao tempo e ao espaço (abordagem reducionista/abordagem holística) e principalmente, exigirá uma abordagem multidisciplinar.

2. Ancoragem didática das questões sociais: um dos grandes desafios da Educação Ambiental é permitir que os alunos desenvolvam suas opiniões com base na consciência sobre a realidade para que sejam capazes de fazer suas escolhas de forma autônoma. Para isso, é necessário que os alunos compreendam os conteúdos científicos e sua epistemologia para identificar controvérsias sobre eles e para analisar suas repercussões sociais, econômicas, políticas e éticas em relação a diversas temáticas (biotecnologias, questões ambientais, escolhas energéticas, globalização, etc.).

3. Ancoragem curricular: situa o currículo no contexto de sua implementação, caracterizando e definindo conteúdos, métodos, avaliação de ações formativas, materiais (livros e manuais didáticos) e planejamento das ações de formação de professores. A matriz curricular precisa considerar o currículo em sua totalidade, colocando-o em uma perspectiva dinâmica. Segundo os autores, neste contexto, a Educação Ambiental, tanto pelas características doconhecimento que mobiliza (questões vivas e contemporâneas), quanto por sua metodologia (baseada em um diálogo participativo) e seus objetivos (abordagem global, construção de valores, escalas espaço-temporais, etc.), exige um redimensionamento curricular para que possa se integrar ao conjunto formativo curricular.

4. Ancoragem psicopedagógica: as contribuições dos estudos psicopedagógicos são importantes na escolha dos conteúdos e das modalidades das atividades educacionais, especialmente em relação ao processo educativo que ocorre na infância. Segundo os autores, a formação dos professores precisa enfocar as questões ambientais desde outras perspectivas, tendo em vista que a ênfase curricular mais tradicional é sobre uma abordagem cognitiva e comportamental, o que parece deixar pouco espaço para a reflexão psicopedagógica sobre as relações entre crianças e seu ambiente. 
Com base nestes elementos de ancoragem apresentados por Girault et al (2006), analisamos uma experiência formativa desenvolvida com estudantes do curso de Pedagogia da Universidade Federal do Paraná (UFPR) ao longo dos anos de 2011 e 2012. O projeto foi desenvolvido no âmbito da Extensão Universitária, especificamente dentro do Programa Licenciar, e teve como título "A práxis da Educação Ambiental nos Centros Municipais de Educação Infantil do município de Curitiba, PR”.

A extensão universitária, em conjunto com a pesquisa e o ensino, formam os pilares do ensino superior no Brasil hoje, em acordo com o artigo 207 da Constituição Federal de 1988. Ao longo da história, o conceito de extensão universitária passou por diversas diretrizes, indo desde a extensão para prestação de serviços à extensão assistencial ou à extensão cidadã, por exemplo. Apesar das diversas variantes do conceito, a extensão universitária sempre esteve, de uma forma ou de outra, relacionando os saberes acadêmicos com a comunidade na qual a academia está inserida ou envolvida.

Na UFPR, as iniciativas de Extensão Universitária desenvolvidas por servidores docentes, técnicos administrativos, discentes e colaboradores externos viabilizam a concepção de universidade cidadã em que a socialização do conhecimento é fundamental para o desenvolvimento social, para a criação e reestruturação de novos conhecimentos e contribuem na solução de problemáticas sociais específicas possibilitando que as comunidades possam desenvolver capacidade de auto-gestão. Além disso, a partir da perspectiva de desenvolvimento sustentável, têm desenvolvido diagnósticos, análises, estudos, proposições e ações que envolvem questões prioritárias da sociedade, com ênfase na transformação e melhoria da qualidade de vida, com um trabalho integrado com a população. Tais iniciativas são realizadas por intermédio de educação continuada em diferentes áreas do conhecimento, de articulação com movimentos sociais, de programação cultural, de difusão científica e tecnológica, de promoção do desporto e lazer e de integração com a educação básica, entre outros. Dessa forma, promove-se a formação de um estudante participativo em uma relação de compartilhamento e troca e de experiências relacionadas à sua futura área de atuação profissional. 
Dentre essas ações, destacam-se os Programas e Projetos de Extensão Universitária. De acordo com a Resolução Extensão - 72/11 CEPE - UFPR, entende-se como Programa de Extensão:

(...) o conjunto articulado de Projetos e outras atividades de Extensão que contemple os quatro princípios estabelecidos no $1^{\circ}$ artigo desta Resolução (Impacto e Transformação, Interação Dialógica, Interdisciplinaridade, Indissociabilidade Ensino-Pesquisa-Extensão), visando resultados de mútuo interesse para a sociedade e para a comunidade acadêmica (p. 7).

Um dos programas que fazem parte dos Programas e Projetos de Extensão Universitária é o Licenciar, que congrega projetos dos diversos cursos de Licenciatura da UFPR. O objetivo geral do Licenciar é apoiar ações que visem ao desenvolvimento de projetos voltados à melhoria da qualidade de ensino nas Licenciaturas da Universidade, através do acompanhamento pedagógico, orientação aos coordenadores, distribuição de bolsas aos licenciandos e organização e promoção de eventos para socialização dos conhecimentos gerados a partir de projetos. Além disso, o Licenciar busca promover a ampliação da formação acadêmica, bem como a produção de conhecimento científico sobre a prática pedagógica, a partir de processos de integração com contextos educativos formais e não formais e enfatizar a integração das Licenciaturas com os diferentes níveis da Educação Básica da Rede Pública, bem como com os contextos não-formais da educação, proporcionando o desenvolvimento de ações que assegurem a indissociabilidade entre teoria e prática na formação do licenciando.

No caso específico deste trabalho, o projeto inseriu um grupo de estudantes do curso de Pedagogia no cotidiano de um Centro Municipal de Educação Infantil (CMEI) de Curitiba. Nesta oportunidade, além das vivências diretas com as crianças, os estudantes puderam conviver e analisar as práticas das professoras e educadoras de infância, mais especificamente aquelas que se referem a Educação Ambiental.

\section{O DESENVOLVIMENTO DO PROJETO EM UM CENTRO MUNICIPAL DE EDUCAÇÃO INFANTIL}

O projeto "A Práxis da Educação Ambiental nos Centros Municipais de Educação Infantil de Curitiba, PR” ocorreu ao longo dos anos de 2011 e 2012. 
Participaram deste projeto um total de cinco bolsistas, todas alunas do curso de Pedagogia da UFPR. O relato aqui apresentado toma por base o relatório apresentado ao final desta experiência de dois anos.

No ano de 2011, o projeto teve como objetivo conhecer práticas e discursos de docentes dos CMEIs de Curitiba no que se refere à temática educativo-ambiental, a partir de um estudo qualitativo. Durante os oito meses letivos de execução do projeto, foram realizadas as seguintes atividades:

- Reuniões de estudo e aprofundamento teórico para todos os membros da equipe;

- Leitura de textos e artigos sobre a temática ambiental;

- Definição dos CMEIs onde seriam realizadas as atividades;

- Visita aos três CMEIs selecionados;

- Diagnóstico dos três CMEIs selecionados;

- Realização de entrevista com as professores e gestoras das três instituições selecionadas;

- Aplicação de questionários em um dos CMEIs selecionados;

- Análise das entrevistas e dos questionários realizados;

- Levantamento e seleção de atividades para a Oficina de Educação Ambiental, desenvolvida com o objetivo de formar os professores;

- Realização da Oficina de Educação Ambiental em um dos CMEIs;

- Intervenção sistemática com as crianças do CMEI para inserção da temática ambiental em suas atividades;- Levantamento da bibliografia sobre Educação Ambiental existente no acervo da UFPR;

- Compilação dos dados e escrita do Relatório Final.

O estudo e aprofundamento teórico para preparação das atividades de campo ocorreu principalmente nos dois primeiros meses de projeto. Os textos foram escolhidos coletivamente e, a cada semana, uma nova leitura era realizada e discutida em grupo. A partir das discussões, novos textos eram selecionados para os encontros seguintes. Também durante este período, foi realizado um levantamento de toda a bibliografia sobre Educação Ambiental existente no acervo da Universidade Federal do Paraná.

Após a definição, pela Secretaria Municipal de Educação, dos três CMEIs que poderiam participar do projeto, foi realizada uma visita em cada um deles para se firmar um primeiro contato, explicar os objetivos do projeto e definir um cronograma. 
Nesteprimeiro contato, foram realizados, através de reuniões com as pedagogas e diretoras, diagnósticos individuais dos CMEIs investigando mais a fundo suas características institucionais (como número de alunos, quadro de funcionários, formação dos funcionários, rotina etc.), a comunidade ao seu redor (como renda média das famílias, perfil de trabalho, participação no CMEI etc.) e a percepção das diretoras, pedagogas, professoras e educadoras sobre a temática ambiental.

Em virtude da grande demanda de atividades, somente o CMEI Uberaba participou da segunda fase do projeto, ou seja, a aplicação de questionário e realização de entrevistas que fundamentaram a elaboração da oficina pedagógica sobre Educação Ambiental na Educação Infantil.

Para a análise da práxis da educação ambiental neste CMEI, foram definidos oito objetivos: 1) identificar práticas de educação ambiental na educação infantil; 2) identificar iniciativas/práticas individuais de educação ambiental; 3) relacionar práticas de educação ambiental com os recursos teóricos utilizados pelas professoras; 4) descrever o perfil formativo-profissional das docentes e educadoras; 5) analisar a concepção das professoras em relação à problemática ambiental da comunidade em que o CMEI está inserido; 6) compreender a finalidade pedagógica da horta na escola; 7) identificar o nível de envolvimento da comunidade nas atividades de educação ambiental; e 8) identificar a rede de colaboração que o CMEI estabelece para desenvolver práticas de educação ambiental.

Para alcançar cada um desses objetivos, foram utilizadas três fontes de dados: a observação, a análise de documentos e os questionários. Os dados da observação foram as informações coletadas na primeira conversa com a pedagoga e a diretora e o reconhecimento visual do espaço físico do Centro. A análise de documentos foi a investigação de documentos escritos encontrados na escola e que fizessem referência à prática de educação ambiental no CMEI, como os Planos Anuais, por exemplo. Os questionários foram fornecidos impressos e digitalizados às professoras e educadoras. A proposta inicial era que fossem realizadas entrevistas com todas as docentes do Centro ou, pelo menos, com uma de cada turma. Porém, novamente pela escassez de tempo, optou-se por substituir as entrevistas por questionários que as professoras/educadoras pudessem responder sozinhas, quando tivessem disponibilidade. Ainda assim, foi realizada uma entrevista com uma das professoras. 
Através da análise do diagnóstico dos dados coletados e das respostas dos questionários, foram selecionadas diversas atividades de Educação Ambiental possíveis de serem realizadas na Educação Infantil e que foram apresentadas na Oficina realizada para as professoras/educadoras do CMEI.

A Oficina foi realizada em dois dias, visto que não foi possível a liberação do quadro inteiro de funcionárias de uma só vez para participarem das atividades em um único dia. Desta forma, a Oficina foi realizada em uma segunda-feira pela manhã e novamente na terça-feira de manhã. Também foram apresentadas na Oficina as experiências vividas pelas Bolsistas com Educação Ambiental na Educação Infantil. Ao final das apresentações, foi realizada uma atividade prática com as professoras/educadoras e foi distribuído um material impresso para cada uma delas com a descrição detalhada de todas as atividades propostas pelos formadores.

No ano de 2012 o projeto continuou a ser executado no mesmo CMEI do ano anterior, mas o trabalho foi muito mais voltado à prática do que à investigação. Com base no diagnóstico realizado no primeiro ano e através de reuniões com a pedagoga, diretora e professoras, foi criado um Projeto de Educação Ambiental para ser aplicado semanalmente pelas bolsistas (em cooperação com as professoras/educadoras), em duas turmas do CMEI, proporcionando à equipe do CMEI a experiência da aplicação de um projeto de Educação Ambiental de longo prazo.

O Projeto de Educação Ambiental para a Educação Infantil foi elaborado em parceria entre as bolsistas, a professora-orientadora do projeto na UFPR e as professoras e educadoras do CMEIs. As turmas que participaram do Projeto foram o Maternal III (30 crianças com faixa etária de 3 a 4 anos) e o Pré (30 crianças com faixa etária de 4 a 5 anos). A escolha destas turmas para o Projeto foi devido ao número de bolsistas disponíveis (somente três) e à preferência da diretora de que o Projeto fosse aplicado nas turmas de crianças um pouco mais velhas.

O Projeto teve como base as atividades de Educação Ambiental que foram apresentadas na Oficina de Educação Ambiental no ano anterior (2011), para as professoras do CMEI. Como a proposta era a de criar um projeto que tivesse relação com os outros projetos que as professoras estivessem desenvolvendo, ele foi sendo escrito e aplicado aos poucos, na medida em que as propostas das professoras fossem se efetivando. O Projeto se constituiu de quatro principais unidades: Unidade $1-\mathrm{O}$ 
Sistema Solar e o Planeta Terra; Unidade 2 - Os Ecossistemas e a Biodiversidade; Unidade 3 - O Lugar em que Vivemos; e Unidade 4 - O Nosso Corpo.

A primeira unidade - O Sistema Solar e o Planeta Terra - foi trabalhada a partir da leitura do livro "O Pequeno Príncipe", de Antoine de Saint Exupéry. O objetivo da unidade era trabalhar principalmente o aspecto que todos os planetas do Sistema Solar têm em comum, que é a relação com o Sol. Desta forma, trabalhou-se também a questão da interdependência que os elementos têm entre si e, com isso, a questão da vida na Terra e quais os elementos fundamentais para que exista a espécie humana no nosso planeta.

Na segunda unidade - Os Ecossistemas e a Biodiversidade - partiu-se da discussão sobre os aspectos indispensáveis para a existência da espécie humana no planeta Terra e trabalhou-se principalmente os aspectos indispensáveis para que haja outras formas de vida no planeta, como para espécies de animais que vivem na água ou para plantas que vivem no deserto, por exemplo.

Já na terceira unidade - O Lugar em que Vivemos - o objetivo foi estimular nas crianças uma maior percepção do ambiente em que elas vivem, seja dos elementos naturais, seja dos elementos criados pelo homem. Explorou-se o ambiente do qual fazemos parte (nossa cidade, nossa casa, nossa escola), porque conhecer o nosso ambiente é conhecer a nossa origem.

Finalmente, na quarta e última unidade - O Nosso Corpo -, foi trabalhada a valorização da singularidade e a contextualização do ser humano como parte integrante do meio em que vive através de atividades de autoconhecimento, envolvendo aspectos físicos, mentais e emocionais das crianças. Foram trabalhadas as diferentes concepções de ser humano e de como cada cultura possui uma forma singular de perceber a si mesmo, como os indígenas, por exemplo, que tem uma percepção de si muito diferente da do homem branco ocidental, que vive em uma sociedade que supervaloriza o pensamento racional.

As bolsistas foram à escola uma vez por semana, todas as semanas de junho a novembro, salvo algumas exceções, totalizando 16 dias de atividades práticas no CMEI. O horário estipulado para as atividades do Projeto foi determinado seguindo a rotina das próprias crianças. Sempre no período da tarde, elas acordam do "soninho" e vão tomar 
um lanche, que se encerra por volta das $15 \mathrm{~h}$. Depois, às $17 \mathrm{~h}$, as crianças tomam a sopa e foi nesse intervalo entre refeições que o Projeto foi executado.

\section{DESCOBERTAS A PARTIR DA PROPOSTA FORMATIVA PROPOSTA AOS ESTUDANTES DO CURSO DE PEDAGOGIA}

Esta experiência problematizou - e nos permitiu refletir- sobrevários aspectos descritos nas ancoragens de Girault et al (2006). O espectro de questões que emergem deste contextonos permitiu repensar as questões epistemológicas, didáticas, curriculares e psicopedagógicas que permeiam o cotidiano da Educação Infantil e das demandas em relação aos professores. Revelou, ainda, a necessidade de se adensar os debates sobre a inserção da temática educativo-ambiental nas propostas formativas das instituições de ensino superior, pois estas têm papel essencial no processo de produção de conhecimentos e na incorporação das atuais dimensões científicas, tecnológicas e culturais relacionas à pesquisa na educação (MORALES; KNECHTEL, 2012).

Foi possível perceber, no projeto extensionista desenvolvido, aspectos das quatro ancoragens propostas por Girault et al (2006) para a formação de professores. A ancoragem epistemológica (compreensão do tema e a construção do conceito) foi realizada ao longo dos dois anos de projetos, nos grupos de estudo e na leitura de textos específicos sobre a Educação Ambiental. Do ponto de vista desta ancoragem, o campo da educação ambiental se caracteriza pela diversidade de áreas de conhecimentos que se integram para a compreensão das questões ambientais e pela complexidade destas relações. Segundo Campos e Carvalho (2015, p. 120),

\footnotetext{
Não existe uma única concepção de educação ambiental e, apesar de esta diversidade ser enriquecedora, também dificulta a reflexão e a ação, por falta do consenso de um eixo de conhecimento de referência. Porém, em um aspecto todos estão de acordo: a educação ambiental pretende propiciar uma mudança de pensamento e a conduta das pessoas e dos grupos sociais; a divergência está em como se caracteriza esta mudança: seu sentido, seu conteúdo, as estratégias utilizadas, a amplitude da mudança proposta, entre diversos outros aspectos.
}

Neste sentido, a falta de consenso conceitual, ou as variáveis interpretativas em relação ao conceito de Educação Ambiental, não podem se constituir como um elemento limitador/dificultador para a formação de professores, pois existe um acúmulo de produção científica nas últimas décadas que aporta elementos suficientes para compreender as tendências e principais abordagens do campo. Além disto, ao recorrer 
aos estudos sobre a história da constituição do campo da Educação Ambiental (ÁRIAS ORTEGA, 2013), há consenso em relação a sua origem no bojo dos movimentos ambientalistas e de "contra-cultura" dos anos 1960 e 1970, período marcado por uma pauta reivindicativa de base ecológica sustentada pela necessidade de "estabelecimento de novos valores para incorporar a dimensão ambiental não apenas na educação, mas em todo o tecido social, em todas as manifestações simbólicas e materiais do ser humano" (LAYRARGUES, 2001, p. 8).

Já aspectos da ancoragem didática puderam ser percebidos principalmente na etapa de diagnóstico aprofundado dos CMEIs para a elaboração da proposta que seria executada no segundo ano do projeto. Nesta etapa as bolsistas puderam desenvolver a habilidade de relacionar conteúdos científicos e sua epistemologia na identificação e no diagnóstico da realidade social concreta na qual iriam trabalhar, para assim, poderem pensar na melhor abordagem possível para aquelas crianças daquele contexto.

Apesar da rigidez curricular do curso de Pedagogia, a ancoragem curricular pôde ser percebida no desenvolvimento do projeto na medida em que as bolsistas tiveram a oportunidade de relacionar, na prática, diversos conceitos e conteúdos aprendidos de forma fragmentada durante a graduação. Ao pensar a estrutura dos cursos de formação de professores, que em sua maior parte, apontam para tendências disciplinares e, por vezes, pouco integradas, encontramos uma dificuldade de inserção da temática ambiental. O processo de transversalização da temática ambiental em todos os níveis de ensino, e em especial nos cursos de formação de professores, ainda se manifesta em tentativas pontuais e descontinuadas. As metodologias empregadas, a forma de avaliação dos processos, as temáticas abordadas, embora inovadoras em sua ação, desde o nosso ponto de vista, ainda carecem de perspectivas mais críticas em relação às macroestruturas sociais, políticas e econômicas. No entanto o exercício realizado no projeto de extensão permitiu às bolsistas repensarem a produção e a aplicação de conhecimento de uma outra forma.

Na proposta do projeto desenvolvido, ao abordar a ação educativo-ambiental para crianças de 0 a 5 anos, fez-se necessário refletir sobre a ancoragem psicopedagógica do processo, tendo em vista que é um desafio pensar em projetos permanentes e emancipatórios, que considerem a importância de compreender a percepção e a sensibilização das crianças em relação ao meio ambiente, pois esta 
compreensão de mundo das crianças é inicial e muitas vezesos professores demonstram despreparo teórico e metodológico para lidar com essas questões ou mesmo com as necessidades deste período do desenvolvimento humano.

Para a estruturação da proposta formativa com os estudantes do curso de Pedagogia, ao buscar aprofundamento sobre os aspectos sociais, psicológicos, educativos e políticas da Educação Infantil para fundamentar a formação dos professores, foi possível perceber a necessidade de conceber esta etapa educativa com suas características identitárias próprias, que responda às suas propostas formativas essenciais, conforme aponta Frabboni (1996). Segundo a autora, dentre as principais metas para a formação de crianças, estariam a garantia de que elas tenham condições de frequentar os centros de Educação Infantil; a garantia de vivências culturais enriquecedoras nestes espaços; e a qualificação pedagógica e didática dos profissionais para atuar na Educação Infantil.

\section{CONSIDERAÇÕES FINAIS}

Ao longo do desenvolvimento do projeto foi possível perceber um avanço em relação a formação das estudantes do curso de Pedagogia. A temática ambiental para elas se constituiu em um novo campo de pesquisa a ser aprofundado em sua formação. A cada encontro novos aspectos eram discutidos, desde as questões conceituais, até a instrumentalização metodológica que exigia a ação, conforme aponta a ancoragem didática apontado por Giralt et al (2006). Essas descobertas nos permitiram perceber os limites de uma estrutura curricular atrelada à tradição disciplinar, que nem sempre responde às necessidades formativas dos professores.

Ao longo do processo, também foi possível perceber que os discursos das professoras e educadoras entrevistadas nos CMEIs ainda são fortemente marcados por uma tendênciaecológica e pautados em metodologias tradicionais, próprias da cultura escolar. Podemos observar práticas de Educação Ambiental ainda centradas na descrição da natureza e dos problemas ambientais, desconsiderando as causas e implicações de ordem política, social e econômicas do processo. No entanto a presença das bolsistas do Licenciar no CMEI teve um grande impacto no processo de sensibilização das professoras para as questões da educação ambiental na educação infantil e, segundo elas, ter gente nova no CMEI participando junto com elas - e não 
fazendo por elas - do planejamento, execução e avaliação do projeto foi uma excelente experiência profissional e pessoal, na medida em que puderam ver e vivenciar uma outra educação ambiental, em um projeto com atividades pensadas e interligadas entre si, transcendendo a lógica de práticas naturalista ou descontinuadas.

A análise desta realidade nos fez perceber a existência de um distanciamento entre a produção teórica no campo da Educação Ambiental, a ação dos professores em seus espaços de trabalho e as propostas formativas dos cursos de Pedagogia. Por outro lado, o desenvolvimento de projetos paralelos à estrutura curricular dos cursos de formação de professores é importante para vincular a formação acadêmica a experiências profissionais concretas, que visem o reconhecimento do campo de trabalho e a possibilidade de experienciar a intervenção educativa relacionada a novas temáticas.

Por mais simples que possam parecer as atividades de educação ambiental feitas com crianças pequenas, neste projeto foi possível perceber uma mudança efetiva de atitudes e valores nas crianças, como comentaram, nas entrevistas, as professoras em relação à mudança de atitude das crianças em decorrência da execução do projeto. Se um projeto realizado uma vez por semana teve um impacto tão grande nas crianças, quão grande seria o impacto de um projeto de longo prazo, bem pensado e bem estruturado, com atividades mais frequentes e com financiamento e apoio de entidades administrativas?

Por fim, espera-se que estas reflexões possam se constituir em uma contribuição relevante para o avanço dos processos socioambientais, bem como uma contribuição para a qualificação e melhoria dos procedimentos relativos a educação ambiental, em especial no âmbito da Educação Infantil, uma fase fundamental no desenvolvimento dos sujeitos.Além disso, espera-se que esta experiência relatada, tão rica no processo de formação de futuras professoras pedagogas, possa servir de exemplo a quem busca alternativas e mudanças na qualidade da formação dos professores da Educação Básica no Brasil.

\section{REFERÊNCIAS}

ÁLVAREZ-GARCIA, O;SUREDA-NEGRE J;COMAS-FORGAS, R. Environmental Education in Pre-Service Teacher Training: A Literature Review of Existing Evidence. Journal of Teacher Education for Sustainability, vol. 17, n. 1, pp. 72-85, 2015. 
ÁRIAS-ORTEGA, M. A. La construcción del campo de la educación ambiental: análisis, biografías y futuros posibles. Guadalajara, Jaleco:EditoraUniversitaria, 2013.

BERRYMAN, T. Des pistes pour institutionnaliser une éducation relative à l'environnement dans la trajectoire obligatoire de la formation initiale à l'enseignement primaire. Éducation Relative à l'Environnement, Vol. 6, pp. 137-158, 2006-2007.

BRASIL. Lei No 9.795, de 27 de abril de 1999: Lei da Educação Ambiental. Brasília, 1999. Disponível em: <http://presrepublica.jusbrasil.com.br/legislacao/110259/lei-daeducacao-ambiental-lei-9795-99> Acesso em: 26/10/2017.

BRASIL. Lei N ${ }^{\circ}$ 17.505, de 11 de janeiro de 2013. Política Estadual de Educação Ambiental e Sistema de Educação Ambiental. Curitiba: 2013. Disponível em: $<$ http://www.legislacao.pr.gov.br/legislacao/listarAtosAno.do?action=exibir\&codAto=8 $5172 \&$ indice $=1 \&$ totalRegistros $=57 \&$ anoSpan $=2013 \&$ anoSelecionado $=2013 \& \mathrm{mesSelec}$ ionado=0\&isPaginado=true $>$ Acesso em: 27/10/2017.

FERREIRA, C. O meio ambiente na prática de escolas públicas da rede estadual de São Paulo: intenções e possibilidades. Tese de Doutorado. Faculdade de Educação, Universidade de São Paulo, São Paulo, 2011.

FRABBONI, F. La educación del niño de cero a seis años.Madrid:Cincel, 1996.

GIRAULT, Y. et al (2006) La formation des enseignants dans le cadre de l'éducation à l'environnement pour un développement durable : problèmes didactiques. Éducation relative à l'environnement, v. 6, pp. 119-136, 2006-2007.

HENN, R, BASTOS, F. P. “Desafios Ambientais na Educação Infantil”. Revista Eletrônica do Mestrado em Educação Ambiental. Rio Grande, v. 20, pp 329-349,janjun/2008.

LAYRARGUES, P. Prefácio. In: SANTOS, J. E.; SATO, M. A contribuição da Educação Ambiental à Esperança de Pandora. São Carlos: Rima, pp. 13-18, 2001.

MEC. Parecer CNE/CP n 5 de dezembro de 2005. Diretrizes Curriculares Nacionais para o Curso de Pedagogia. Disponível em <http://portal.mec.gov.br/escola-degestores-da-educacao-basica/323-secretarias-112877938/orgaos-vinculados82187207/12991-diretrizes-curriculares-cursos-de-graduacao>. Acesso em: 27/10/2017. 
MORALES, A.G.; KNECHTEL, M.R. A universidade e a formação em educação ambiental na perspectiva multicultural: considerações e possibilidades. In: MORALES, A.G. et al. Educação ambiental e multiculturalismo. Ponta Grossa: Editora UEPG, 2012.

SATO, M; SOUZA, V; MARCELINO, W; BERNARDO, B; DELAI, T. Horta é saúde: educação científica e ambiental no Ensino Fundamental. In:Anais do XI Congresso Nacional de Educação - EDUCERE. Curitiba: PUC, pp. 30.549-30.559, 2013.

SOCZEK, D; HAIDUKE, I. Formação de Professores e Educação Ambiental: reflexões e apontamentos. In: Anais do XI Congresso Nacional de Educação - EDUCERE. Curitiba: PUC, pp. 30.154-30.167, 2013.

TEIXEIRA, C; OLIVEIRA, M. A Temática Ambiental na Educação: o conhecimento em construção. In: Anais do VII Encontro Nacional da Anppas. Brasília, 2008.

TORALES-CAMPOS, M. A.; CARVALHO, A. M. "Desafios emergentes na ação educativo-ambiental: uma experiência em centros de educação infantil em Curitiba-PR". Revista Holos, Ano 31, Vol. 5, pp. 119-129, ago/2015. 